\title{
Mulheres no Esporte: Corporalidades e Subjetividades
}

Miriam Adelman

Resumo: Estudos sobre corporalidade e subjetividade que trabalham a partir da premissa da profunda imbricação da construção de corpos e identidades vêm adquirindo um espaço cada vez maior na teoria social contemporânea. Dentro destes, vem à tona o problema da centralidade dada a determinados "projetos do corpo" na cultura contemporânea, que têm uma forte dimensão de gênero e agem de uma maneira particular sobre a subjetividade feminina. Neste trabalho, reflito sobre resultados de pesquisa minha em duas modalidades esportivas - o do vôlei, e do hipismo clássico - com o intuito maior de discutir as possibilidades do esporte servir como um espaço de transgressão, empoderamento, e/ou disciplinamento patriarcal das mulheres.

Palavras-Chave: Mulheres. Esporte. Corporalidade.

O campo das práticas esportivas e corporais é, com certeza, um terreno extremadamente fértil para testar hipóteses sobre as mudanças nas relações e representações de gênero na sociedade contemporânea, um lugar particularmente sensível para indagar os rumos de uma cultura em transição - transição para padrões mais igualitários, mais "andróginos", ou talvez, avançando embora lentamente no sentido de uma certa "despadronização". O esporte, em particular, tornou-se durante mais de um século, o lugar de disputas intensas sobre o que pode/dever fazer um "corpo masculino" ou um "corpo feminino", tanto pelo lugar central que ocupava na construção de novas formas mais "pacificadas" da construção da masculinidade (Oliveira, 2004) quanto pelo que isto poderia significar para as mulheres que, desde a segunda metade do século XIX vinham lutando contra normas de feminilidade que, como disse Maria Rita Kehl, estreitavam demais os roteiros que elas tinham à disposição para a construção de uma vida. Essa feminilidade impunha a domesticidade como "norma" - embora

Movimento, Porto Alegre, v.12, n. 01, p. 11-29, janeiro/abril de 2006 
esta de fato tenha sido "privilégio" de raça e classe - e implicava em fortes controles sobre os corpos das mulheres - sua sexualidade, sua liberdade de movimento, e seu uso do espaço urbano no qual o esporte e as atividades físicas tornavam-se uma forma de lazer cada vez mais visível. É para esse contexto que Silvana Goellner, historiadora do esporte e da educação física, fala do mundo esportivo como um território "permeado por ambiguidades ... simultaneamente, fascinava e desassosegava homens e mulheres, tanto porque contestava os discursos legitimadores dos limites e condutas próprias de cada sexo, como porque, por meio de seus rituais, fazia vibrar a tensão entre a liberdade e o controle das emoções, e também de representações de masculinidade e feminilidade "(Goellner, 2004:367) Goellner, junto com o que hoje são muitas outras estudiosas da área do esporte, põe a nossa disposição a história da luta de mulheres que em muitas partes do mundo foram as pioneiras na abertura do mundo do esporte à participação feminina, que chega nos últimos tempos a um momento em que as mulheres participam quase todas as modalidades esportivas, embora a maior parte destas esportes ainda organizem-se pelas categorias de "sexo" (gênero) ${ }^{1}$, e continua sendo comum ver emergir polêmicas que tem como sub-texto, ansiedades relativas aos limites da desconstrução das fronteiras entre os sexos (gêneros).

Por outro lado, nossa atual "cultura da transição" traz algumas dificuldades particulares, de caráter teórico, para quem trabalha na área de estudos de gênero, e para quem deseja estudar o esporte como espaço de transgressão - e/ou de normatização - de identidades e corporalidades generificadas. Pois resulta cada vez mais complicado abordar temáticas sobre "identidades" e subjeti-

${ }^{1}$ Aparentemente no esporte, se estaria trabalhando com essa "diferença mínima" da anatomia dos corpos, mas como aponta Judith Butler, valer-se de uma distinção sexo (biológico) /gênero (cultura e "papel social") merece problematização, sendo que tal distinção pressupõe que teríamos acesso a algum momento prévio à cultura e a nosso próprio esforço cognitivo e linguístico de apropriação do mundo.

Movimento, Porto Alegre, v.12, n. 01, p. 11-29, janeiro/abril de 2006. 
vidades na sua relação com o gênero, e os perigos de reproduzir as antigas dicotomias que homogeneizam as categorias de "homem" e "mulher" parecem enormes, especialmente num momento em que movimentos sociais e culturais ressaltam a presença de pessoas transgêneros, e de diversas formas de produzir "interrupções subversivas" nas cadeias de significação que a teórica queer Judith Butler aponta como a base discursiva da ordem de gênero fundada numa "matriz heterosexual". ${ }^{2}$ Exigem-se complexas problematizações da relação entre "biologia" e "cultura", das diversas capacidades, destrezas e formas expressivas dos corpos e das pessoas, e sobre as múltiplas possibilidades de re-significação fornecidas pela cultura pós-moderna atual ( a partir, com certeza, de persistentes lutas, conflitos, e negociações ) Mas ao mesmo tempo, como a filosofa feminista Susan Bordo (1994) nos adverte, estamos ainda longe de um momento "pós-gênero", as práticas subversivas ainda não se afirmam como majoritárias, e a cultura pós-moderna, atrelada ainda aos discursos hegemônicas disseminados poderosamente nos meios de comunicação de massas, produz a cada momento novas formas de disciplinar os corpos e os sujeitos, segundo critérios dicotômicos e desiguais sobre o que pode/dever ser e fazer, uma mulher, ou um homem.

A escritora feminista Susan Brownmiller uma vez definiu $a$ feminilidade como estética da limitação. Se com isso resumem-se os impulsos dominantes de vários séculos de cultura moderna, entende-se bem porque o esporte - prática que convoca, pelo menos nas suas modalidades competitivas, a "desafiar os limites" das competências corporais - iria tornar-se um cenário de muitos conflitos e lutas sobre o que pode ser/fazer uma mulher. Para as mulheres, torna-se uma disputa por acesso a espaços, legitimidade, e recursos materiais e simbólicos, que encena de forma muito sensível, a luta maior para ter controle sobre o próprio corpo, e

${ }^{2} \mathrm{~A}$ correspondência normativamente imposta, entre os termos: macho/homem/masculino/ objeto de desejo=mulher; fêmea/mulher/feminino/objeto de desejo=homem.

Movimento, Porto Alegre, v.12, n. 01, p. 11-29, janeiro/abril de 2006. 
sobre a vida. É um conflito que envolve uma série de atores sociais: homens e mulheres como indivíduos e como familiares, o Estado (com um grande investimento na definição de "deveres", "direitos" e "funções sociais" para cada sexo) $)^{3}$, profissionais da saúde e da educação, a imprensa e as novas instituições esportivas, entre outros.

$\mathrm{O}$ avanço das mulheres no mundo do esporte, desde o espaço muito limitado que tinham na época em que a noção de fragilidade feminina imperava, até a gradual conquista de atuação esportiva diversificada tanto a nível do esporte amador quanto profissional, é um fenômeno amplamente reconhecido hoje em dia. Mas, como comentei acima - continua sendo um terreno muito sensível e que potencialmente pode nos dizer muito sobre o status atual das mudanças sociais e culturais no âmbito das relações de gênero. Quais as consequiências maiores da atuação esportiva das mulheres numa cultura que supostamente abandonou o ideal da "fragilidade feminina" e embarcou na construção normativa de uma "cultura fitness"? Quais as representações hegemônicas das atletas na mídia? A antiga preocupação com a "masculinização" das mulheres que se dedicam ao esporte continua pautando comportamentos e julgamentos? E -talvez a questão mais central ainda como é que as próprias atletas vivem e interpretam suas experiências no mundo do esporte, e o que podemos dizer sobre as formas em que a prática de esporte, a nível profissional e/ou amador, estruturam a subjetividade e a identidade das mulheres que se envolvem nela? Estas perguntas - algumas das perguntas que orientam o que hoje é um vasto campo de pesquisa no Brasil e no mundo - também me conduziram numa pesquisa comparativa realizada em Curitiba, vários anos atrás, com dois grupos de atletas mulheres com características bastante diferentes. Um grupo, a

${ }^{3}$ No Brasil, o Estado não hesita em promover legislação que proíbe a participação das mulheres em determinadas atividades esportivas.

( Ver Goellner, op. cit.)

Movimento, Porto Alegre, v.12, n. 01, p. 11-29, janeiro/abril de 2006. 
das jogadoras da seleção nacional de vôlei, caracterizava-se pela inserção no "grande mundo" esportivo nacional, ou seja, pertenciam a um time e um esporte integrados aquilo que o sociólogo inglês Joseph Maguire chamou de "global sport media complex". Participes deste contexto midiático e espectacularizado - sustentado por poderosas organizações esportivas locais e globais elas adquirem acesso a ascensão social, ao prestígio e às vantagens materiais de uma vida profissional no esporte ${ }^{4}$. Mas também - como a mesma pesquisa punha em evidência - este campo esportivo também usufrui de convenções patriarcais do disciplinamento e espectacularização do corpo feminino, talvez mais do que fomentar um espaço de desafio às definições normativas da feminilidade. ${ }^{5}$

O outro grupo, a das amazonas do hipismo clássico, trata-se evidentemente de um grupo de atletas que praticam um esporte de elite e que sustenta vínculos mais tênues com o grande complexo esporte. Contudo, embora mais longe dos holofotes da mídia, os praticantes do hipismo clássico se movimentam num mundo esportivo que, como enfatizaria o grande sociólogo francês Pierre Bourdieu, não deixa de encenar processos sociais de distinção (de classe). Ao mesmo tempo, desde uma perspectiva de gênero, é um campo esportivo que permite testar algumas idéias sobre práticas esportivas e corporais como espaços de transgressão.

Meu interesse em pesquisar as amazonas foi instigado inicialmente por uma série de artigos que apareceram na seção esportiva da Folha de São Paulo em 1995, sugerindo que o hipismo promovia a "igualdade entre os sexos" ( ver Adelman, 2003; 2004). A pesquisa bibliográfica de uma primeira fase - uma revisão da história das mulheres nos esportes eqüestres - me conduziu pelos

${ }^{4}$ Como sabemos o esporte é via de ascensão social para homens de camadas populares, e pode sê-lo também para algumas mulheres - ainda com menor status de celebridade e menores salários!

${ }^{5}$ Para mais sobre a pesquisa, ver Adelman (2003).

Movimento, Porto Alegre, v.12, n. 01, p. 11-29, janeiro/abril de 2006. 
labirintos de todo um mundo de transgressões femininas: as mulheres que desde final do século XIX, participavam - particularmente nos EUA e na Europa - do circo, do rodeio, e de alguns outros contextos nos quais, como o mesmo nome de "amazona" sugere, elas exercitavam sua competência em atividades cujos riscos e desafios supostamente descaracterizariam um sujeito feminino. Temos acesso a documentação histórica que preserva as estórias das quase legendárias "mulheres que ousavam" - figuras então excepcionais ${ }^{6}$, como a artista alemã que atuava no famoso circo norteamericano Barnum \& Bailey, Katie Sandwina (Davis, 2002; 82-83) e Lucille Mulhall - que ganhou reconhecimento na imprensa da época como "America's first cowgirl". Esta, nascida em 1885, em 1900 já se apresentava em NY como integrante experiente do rodeio que mostrava, para os habitantes das grandes cidades, atividades espectacularizadas encenadas para captar um pouco do "espirito da fronteira" do oeste para pessoas que tanto geograficamente quanto nos costumes do cotidiano estavam muito distantes da mesma. ${ }^{7}$

Ao longo do século XX, o rodeio nos EUA foi se profissionalizando, nos moldes do esporte contemporâneo, criando nesse processo um circuito alternativo para mulheres. Embora isto permitisse que mais mulheres pudessem viver dessa atividade, teve também o efeito de reforçar a noção delas não serem as competidoras legítimas dos homens. Noutras modalidades dos esportes eqüestres, algumas mulheres pioneiras também se destacaram pelas lutas pela participação e a visibilidade. Neste sentido, o hipismo clássico tem

6 "As forçudas" como as chama Silvana Goellner: "...as mulheres que faziam exibições de força física em casas de espetáculo, circos e music halls nos Estados Unidos e na Europa. Mulheres que tiveram certa projeção e eram reconhecidas pela atuação que faziam nesse sentido, cujo esço fisico desmistificava várias das representaçoes que se tinha ao respeito do corpo teminino nesse mogilidade, do recato e do medo de que elas pudessem ficar com o fisico dos homens se fizessem muito esforço, em especial em esportes considerados violentos. Essas mulheres, que chamo de 'forçudas', em sua grande maioria casaram-se e foram mães, contrariando muito do que se falava delas". (Goellner, 2004: 364)

${ }^{7}$ Evidentemente, contribuindo fortemente para a produção de mitos e ideologias sobre a nação norteamericana.

Movimento, Porto Alegre, v.12, n. 01, p. 11-29, janeiro/abril de 2006. 
algumas particularidades, pois a pesar da histórica participação das mulheres inglesas nas artes equestres - inclusive na caça da raposa, saltando os mesmos obstáculos do que seus companheiros, a pesar da grande desvantagem de serem obrigadas a montar com as duas pernas para o mesmo lado da sela! - é só em nos anos do pós-guerra que uma amazona inglesa, Pat Smythe, estreia como primeira mulher a participar das provas de salto na história das Olimpiadas. Noutra modalidade, o turfe, é só recentemente que emergiram algumas jóqueis que competem nesse esporte tradicional que exige, particularmente, um cavaleiro ou amazona de pouca altura e baixo peso. Na sua fascinante autobiografia, a mundialmente famosa jóquei norteamericana, Julie Krone, relata a história de sua batalha, nos anos 80 , para poder se inserir profissionalmente nesse campo, tendo que enfrentar a resistência aberta - e muitas vezes, violenta - dos seus colegas homens. Ela comenta: "Eu era a primeira mulher jóquei que realmente ameaçou a posição dos jóqueis homens, e alguns deles simplesmente não queriam ser vencidos por uma 'meninha'. Eu estava lutando para achar um lugar em um esporte que tinha pouca abertura para as mulheres." (Adelman, 2004: 290-291)

Contudo, os esportes eqüestres podem hoje ser citados como um espaço de ampla participação feminina, tanto no Brasil quanto no mundo inteiro. Noutro lugar (Adelman, 2004) discuti uma questão cultura que me pareceu muito significativo, a recorrente associação simbólica entre o cavalo, o ato (prática) de cavalgar e a liberdade feminina, tanto na literatura e nas tradições populares ${ }^{8}$ quanto nos depoimentos das amazonas que entrevistei. Na minha

\footnotetext{
${ }^{8}$ Desde algumas lendas antigas até romances modernos ( ou num senso comum que aparece, muitas vezes, expresso na linguagem do imaginário masculino que sexualiza estas amazonas) Um exemplo particularmente interessante que encontrei foi a importante presença do cavalo no gênero da literatura infanto-juvenil dos EUA que pode ser desigte presença do cavalo no gênero da literatura infanto-juvenil dos EUA que pode ser desig-
nado pelo nome, tomboy literature, que se remete a uma construção cultural norteamericana nado pelo nome, tomboy literature, que se remete a uma construção cultural norteamericana
desde o século XIX, de uma literatura protagonizada por "meninas que sempre quiseram desde o século XIX, de uma literatura protagonizada por "meninas que sempre quiseram meninas que desprezavam todas essas distinções (entre meninos e meninas) e queriam simplesmente, ser livres e sem gênero". (McEwen, 1997:XI)
}

Movimento, Porto Alegre, v.12, n. 01, p. 11-29, janeiro/abril de 2006 
pesquisa comparativa entre mulheres praticantes de hipismo clássico e jogadoras da seleção brasileira de vôlei, diferenças no tipos de narrativa construída sobre a iniciação esportiva me pareceram significativas. As amazonas, nas suas falas, identificavam a origem da sua participação esportiva, numa "paixão" muito forte que elas assumiam -em vários casos, a pesar da oposição familiar - pelo animal e pelo esporte em si. Uma amazona que entrevistei se expressou da seguinte forma: "Eu sempre amei os cavalos, e adorava montar na fazenda da minha família... Mas não sabia, de fato, montar... Então quando vi isso aqui [prova de salto na Sociedade Hípica Paranaense], fiquei maluca. Meu Deus do Céu, que maravilha! Falei para meus pais que estava a fim de entrar na Hípica para aprender a montar e eles disseram que não, que é muito perigoso, para menina não! " Isto contrastava com o relatado pela maior parte das jogadoras, que embora atualmente muito dedicadas a seu esporte -tendo construído fortes identidades como atletas da sua modalidade- tinham em quase todos os casos histórias mais ambíguas sobre sua iniciação na carreira esportiva. Várias delas citavam a insistência da família ou de professores da escola, que tentassem praticar o vôlei, tendo sido identificadas pelo tipo físico - meninas muito altas, que destoavam então do padrão corporal feminino, mas que poderiam compensa-lo com a atividade esportiva. Uma jogadora relatou sua experiência assim: "Eu, quando comecei, tinha 12 anos. Era só no colégio que eu treinava. Comecei a treinar porque tinha problemas de coluna e o médico indicou para eu fazer um esporte, natação ou vôlei. Então entrei na Escolinha por causa disso, não por paixão. Depois eu fui gostando... Se ninguém falasse 'vai treinar', 'vai treinar' [eu não teria ido]... porque eu era alta ai ficavam o técnico do basquete e do vôlei me disputando... 'Eu não quero nada' eu falava . Eu comecei fazer por acaso. Não foi por livre e espontânea vontade. Foi o médico que falou".

Outro ponto no qual emergiu um contraste grande entre as representações da prática esportivas das amazonas e as jogadoras

Movimento, Porto Alegre, v.12, n. 01, p. 11-29, janeiro/abril de 2006. 
diz respeito a sua relação com as concepções hegemônicas de feminilidade que, herdadas de outras épocas, abandonem hoje a noção de "fragilidade feminina" sem deixar de produzir e reproduzir normas vinculadas à construção de um sujeito feminino dependente do olhar do outro para sua (auto) valorização. ${ }^{9}$ As jogadoras não se mostravam livres de ansiedades pelo tipo de julgamento ao qual as atletas continuam expostas, na sociedade atual, de serem "pouco femininas". Disse uma, "eu acho que a gente é muito feminina. Às vezes, as pessoas acham atleta machão. A gente procura ser bem feminina, para ninguém 'encher o saco.' Por ser atleta, ter um corpo definido, todo mundo já [acha]... então procuramos aflorar mais o feminino." Outra ainda afirma a importância do cuidado do corpo, da construção de um "corpo bonito" e muito feminino como elemento central da identidade: "Se eu não jogasse vôlei, eu iria cuidar do meu corpo com certeza, malhar todo o dia. Acho bonito. Mas não gosto de uma coisa muito masculina; quem tem tendência a ganhar músculo muito fácil, acho que fica meio masculino. Quando você coloca uma blusa de manguinha é capaz de estourar a blusa." Outra disse: "A gente se preocupa bastante, porque no esporte usa o corpo, então para isso tem que cuidar bastantes, fazer musculação para reforçar os músculos, para as articulações ...isso é importante não só para o nosso trabalho que é o esporte mas como para fora, para a gente sair com uma saia, tem aquela perna firme, não e aquela magrela, eu acho feio. Então a gente tem que trabalhar bastante o corpo, não só para a vida pessoal como a profissional também."

Inclusive, para a maior parte das jogadoras entrevistadas, era muito importante situar seu esporte particular como pertencendo à categoria dos esportes condizentes à construção ou manutenção da feminilidade. Outros esportes - em particular, o futebol ou o handebol - eram significados como "diferentes" do

${ }^{9}$ Neste sentido, os trabalhos de Susan Bordo (1997) e Joan Brumberg (1997) apresentam evidências e problematizações teóricas importantes.

Movimento, Porto Alegre, v.12, n. 01, p. 11-29, janeiro/abril de 2006. 
seu, e identificados como esportes que "masculinizam" as mulheres que os praticam. A preocupação com a possibilidade de serem julgadas como pouco femininas, fez que algumas enfatizassem o caráter "não comprometido" do vôlei, que é "tão feminino", que, como era lembrado por uma ex-jogadora da seleção, "tinha em outra época" a possibilidade de "comprometer a masculinidade" dos homens que o praticavam, carregando o estigma forte da homossexualidade.

Contudo, esta sensibilidade dos esportes aos estereótipos/ classificações de gênero não era aceita tranqüilamente por todas as entrevistadas. Numa conversa com duas jogadoras, as duas criticavam o que para elas era uma atitude classificatória comum e reprovável de pôr etiqueta nas atletas. Colocando os que assim pensam na ambígua categoria de "eles" -uma estratégia discursiva comum que todos usamos para mostra distanciamento e falta de identificação- uma das duas disse, "O Vôlei eles acham que é feminino, acham que basquete é mais masculino, falam que a mulher do Basquete tem um jeito mias masculino. Mas eu acho que o esporte para a mulher é tudo igual, a diferença vem de fora."

Com certeza, atenção às diferenças entre os dois campos esportivos estudados é absolutamente imprescindível para fazer valer nossas considerações comparativas sobre estes esportes e o que podem contribuir para (re)significar a feminilidade. Envolvem importantes questões que cruzam as três grandes eixos de desigualdade social - os de classe, raça e gênero - e que têm, a sua vez, profundas conseqüências, determinando por exemplo o acesso das atletas a oportunidades e recursos sociais mais amplos, ou tornando a atividade esportiva profissional importante como caminho à ascensão social. As amazonas entrevistadas eram todas brancas e de famílias de classe média ou das elites, fato consoante com o que sabemos sobre o caráter de elite desse campo esportivo. Esta situação se contrasta com a origem social humilde da maior parte das jogadoras que entrevistei, algumas delas negras e oriundas de regiões pobres do país. E permite perceber o contex-

Movimento, Porto Alegre, v.12, n. 01, p. 11-29, janeiro/abril de 2006. 
to social que sustenta a maior liberdade nas "escolhas" no caso das amazonas, no sentido delas serem meninas e mulheres com acesso a maiores opções e recursos culturais e materiais para a construção do projeto de vida, e o contexto inicial de horizontes mais limitados no qual o envolvimento no vôlei se tornou uma estratégia interessante para as jovens que o escolheram. Ao mesmo tempo, me parece muito significativo que as amazonas adotam, em todos os casos, um discurso que questionava muito mais, e muito explicitamente, as expectativas generificadas da sociedade brasileira atual. Elas reclamavam de atitudes familiares que dificultavam o avanço das meninas talentosas no mundo da competição ("Se os pais vêem a menina cair ou se machucar, o pai começa a cortar. Se o menino tiver uma cicatriz na cara é uma coisa; agora a menina não, né?") ou que dificultavam o avanço das profissionais, que como uma grande parte das profissionais de qualquer área, tem que lidar também com responsabilidades domésticas que entram em conflito com as longas horas de treinamento esportivo e o envolvimento nas competições que as levam para lugares distantes. Também mostravam-se muito orgulhosas de desafiar estereótipos sociais como o da "maior coragem" dos homens perante os desafios de um esporte que têm evidentes perigos e questionavam a noção das mulheres serem mais "doces" no trato da montaria, ou menos competitivas dentro nas pistas.

Enquanto o envolvimento no hipismo não aparecia condicionado pela idade ou ciclo de vida das praticantes, as jogadoras tendiam a representar o envolvimento com o esporte profissional como "só uma fase"; uma fase de sacrifícios, e de abrir mão de ter "uma vida normal" como mulher. Várias delas vislumbravam claramente um futuro fora do esporte, dedicadas ao lar e aos filhos que sonhavam ter. Uma delas chegou a explicar a ausência de técnicas e treinadoras de sexo feminino pela falta de vontade das mulheres de continuar nessa "vida sacrificada", dizendo "A maioria não se interessa mesmo. A mulher, é difícil encontrar alguma que fale, 'Eu quero ser técnica. Tudo mundo quer casar e ter filho,

Movimento, Porto Alegre, v.12, n. 01, p. 11-29, janeiro/abril de 2006. 
curtir sua vida ... ficar na quadra ainda? Não há casamento que resiste!" As amazonas, em contraste, reclamaram das assimetrias de gênero que muitas vezes as colocavam na situação - vista por elas como injusta - de "ter que escolher" entre família e vida esportiva. As duas que na época eram casadas, viam sua própria situação como "excepcional", tendo maridos "diferentes" que as apoiavam. Outra, divorciada, falava não sem certo ressentimento das limitação que um casamento e gravidez quando ainda muito jovem tiveram sobre suas possibilidades dela "chegar ao topo" no competitivo mundo do esporte onde ainda poucas mulheres conseguiam chegar - disputar por exemplo uma vaga na equipe brasileira que compete nas Olimpíadas . Duas, ainda solteiras, viam sua dedicação ao hipismo como um fator que limitava sua disponibilidade para relações amorosas mais convencionais, e faziam, em tom de brincadeira, algumas conjeturas sobre as condições que seus futuros namorados teriam que ser dispostos a aceitar. Das jogadoras, só uma, com 29 anos na época de entrevista, colocou a situação em termos mais parecidos com as críticas das amazonas, deixando claro que não estaria disposta a abrir mão de projetos esportivos profissionais. Embora sem se referir concretamente a atitudes discriminatórias ou a falta de apoio dos companheiros esta última, queixa constante dentro do grupo das amazonas apontava para uma assimetria de gênero que podia pesar na vida de uma atleta: "pelo fato de ser atleta, você abre mão de muita coisa, principalmente a mulher. É diferente para o homem que é jogador: ele pode casar, ele pode ter o filho dele. E a gente não tem tempo para programar ... Desde o momento que eu optei por ser jogadora, eu abri mão de tudo... Agora estou começando a pensar, mesmo porque eu estou com 29 anos, uma idade para organizar minha vida fora da parte profissional. Mas desde que não atrapalhe meus objetivos dentro do esporte."

Parece, então, muito mais claro que para as amazonas, a participação no esporte e no mundo eqüestre constitui a base de uma identidade da qual o desafio às convenções sociais da feminilida-

Movimento, Porto Alegre, v.12, n. 01, p. 11-29, janeiro/abril de 2006. 
de faz parte, e da qual elas não pretendem abrir mão. Parece exemplificar o que muitas pesquisadoras da área de gênero e esporte vêem procurando - as formas em que participação esportiva das mulheres possa fomentar o empoderamento feminino, individual e coletiva, e ajudar a desconstruir poderosas normas sociais baseadas nas dicotomias e hierarquias de gênero. Era também uma identidade assumida por elas, em termos basicamente individuais. No caso das jogadoras, eu diria que trata-se de uma situação muito mais ambígua e com algumas contradições particulares. Ouvi delas algumas estórias de enfrentar obstáculos e dificuldades, com muita ênfase no "sacrifício cotidiano" que é exigido do atleta. A frase repetida, de que a vida da atleta "não é normal" mostra, várias coisas: por exemplo, a aceitação de um disciplinamento potencialmente oneroso e do adiamento do tipo de projeto de vida famíliar "normal" para uma mulher. Mas também, sua identificação com esta "não normalidade" porque pertence às caraterísticas de uma pessoa que se torna celebridade, posição que como atletas nos holofotes, elas gozavam. A fama pois, era o outro lado do sacrifício.

A necessidade de se submeter a um regime de treinamento particularmente duro, para obter os ganhos oferecidos, foi relatado desta forma pela jogadora de 29 anos acima citada, "A nossa vida é totalmente dedicada, são 24 horas que a gente passa pensando em vôlei. A gente acorda, têm horário para tudo, a gente tem a comida que eles escolhem, os horários são eles que escolhem. Então é aquela coisa um pouco militar... Então é aquela coisa, você escolheu isso, então vou me dedicar a isso, eu vou seguir as regras deles, vou seguir o que eles querem... É o que a gente escolheu, então a gente tem que obedecer... é um sofrimento, é dedicação total, mas vale a pena." É só no fascinante relato de uma ex-jogadora da seleção, que na época da entrevista tinha mais de quarenta anos, e atua hoje na área de treinamento esportivo popular, que aparece uma reflexão mais parecida com a das amazonas, sobre o esporte como forma de afirmação que alarga o

Movimento, Porto Alegre, v.12, n. 01, p. 11-29, janeiro/abril de 2006. 
espaço de participação social feminina. No relato dela, o envolvimento no esporte está sempre vinculado à procura de uma forma de desenvolvimento pessoal, com uma forte dimensão espiritual e ainda, vinculado ao coletivo. Ela -única menina numa família humilde e numerosa - disse ter tido apoio familiar, numa época quando as famílias brasileiras teimavam mais em não deixar suas filhas se emanciparem, e muito menos, viajarem pelo mundo: "...queria aprender, queria conhecer as coisas, então sempre que eu viajava com a seleção brasileira (a gente viajou o mundo inteiro, conheço o mundo pelo esporte), sempre que tinha uma hora de folga eu ia conhecer um museu, conhecer as pessoas daquele lugar, conhecer a cultura daquele povo ou daquele país. Então o esporte me deu isso tudo. Eu falo que é onde me realizei, porque não é só a quadra ou ter ido para uma seleção, a parte técnica, mas o meio ... vira um veículo que te abre as portas, te proporciona e te leva a muitas opções...". Ela, que chegou a fazer duas faculdades - Economia e Educação Física - também salienta que as condições do mundo esportivo vêm mudando, com o treinamento cada vez mais rigoroso e exigindo das jogadoras uma "dedicação exclusiva". "Hoje”, ela disse, "está muito mais profissionalizado; ganha-se muito mais dinheiro que na minha época"; o lugar de destaque nacional e mediático das jogadoras de vôlei cria um contexto diferente ao de tempos atrás. Ela alega não só que o nível de exigência dificulta que as meninas que pratiquem esporte a nível profissional tenham outros interesses, senão também, que os avanços conduziram a um novo padrão corporal, de mulheres "mais fortes", "mais musculosas". De modo que através do depoimento dela, podemos refletir sobre o caráter contraditório do envolvimento esportivo atual das mulheres no esporte profissional: maiores oportunidades, maior visibilidade, maiores chances até de ascensão social através do mundo esportivo - mas ao mesmo tempo, maior submissão das atletas "às regras do jogo". Estas, a sua vez, não deixaram de exigir das atletas que estão nos holofotes, uma

Movimento, Porto Alegre, v.12, n. 01, p. 11-29, janeiro/abril de 2006. 
compatibilização entre a prática do esporte e normas de feminilidade. Como também aparece no relato desta jogadora, os critérios para bom rendimento no esporte não se divorciam de preocupações com a aparência - a preocupação é muito internalizada pelas próprias mulheres, desde as meninas de 12 e 13 anos que ela treina, até as jogadoras que discutem com muito interesse as escolhas feitas pelas revistas masculinas, que na atualidade até podem "preferir" o tipo de corpo de uma jogadora de futebol para posar nua nas capas.

Assim percebemos com clareza como opera, no atual mundo do esporte espetacularizado, a reprodução de um padrão estético e comportamental que é reforçado também em muitos espaços do cotidiano e disseminado pela mídia - sobre "o que é uma mulher “ - um corpo com determinadas proporções e dimensões, uma mulher desejável e invejável nos termos de uma feminilidade determinado pelo olhar masculino e heterossexista e que se mantém como discursivo hegemônico, agindo sobre as meninas e as mulheres, moldando identidades e subjetividades aos seus desígnios. Pode ser, como disse a Kehl, falando sobre outro momento, que muitas mulheres "gozaram da feminilidade" construída historicamente pelos homens, e de fato não há muito lugar para dúvidas respeito ao grande investimento de muitas mulheres atuais nos discursos hegemônicos, que empurra o "projeto do corpo" esteticamente padronizado para o mais elevado lugar na lista de prioridades, para a construção de identidades e subjetividades .

A pesquisa que expus aqui mostra que o esporte pode seré, muitas vezes - mais um espaço para a "construção de corpos femininos sexualizadas e corpos masculinos poderosos" (Lorber: 1994)) mas também pode viabilizar outras formas das mulheres sentirem, agirem e se representarem. É por isso que me parece tão interessante a fala de uma das amazonas - competidora e instrutora - que entrevistei sobre suas alunas : "Talvez esta seja a melhor parte do que fazemos aqui: as crianças se acostumam com a

Movimento, Porto Alegre, v.12, n. 01, p. 11-29, janeiro/abril de 2006. 
natureza, com sujar suas mãos e roupas, com cuidar de seus cavalos. Melhor do que se tornar 'princesas de shopping', o que acontece muito aqui em Curitiba. E você realmente vê que elas são diferentes, essas meninas que vêm aqui para montar. A parte mais importante do seu dia elas passam aqui, então as idas ao shopping significam menos para elas. Elas crescem ao menos um pouco mais naturalmente."

Talvez uma última parte do meu argumento que ainda precisa de ser explicitada diz respeito à centralidade de questões de corporalidade na construção de identidades e subjetividades, pois de maneira alguma gostaria de despreza-la. Muito pelo contrário - e de acordo com as perspectivas mais interessantes das ciências sociais contemporâneas, que tentam desconstruir o pensamento dicotômico que reforça a antiga distinção ocidental entre "corpo" e "mente", quero reafirmar a importância de construir corporalidades diferentes - mais afastados do poder disciplinar que age, de acordo a uma ordem de gênero hierárquica e sua "matriz heterossexual" - e de acordo a critérios de mercantilização de corpos masculinos e femininos. As reflexões e resultados de pesquisa aqui oferecidos talvez ajudem a pensar e pesquisar mais, os discursos e práticas atuais que constróem corpos/subjetividades/identidades. Esperamos, como sugere a historiadora Denise Sant'Anna, que a cultura de "libertação dos corpos" - principalmente os femininos - de tabus e códigos repressivos, que tomou grande impulso a partir da contestação cultural dos anos sessenta (Sant' Anna, 2000), possa nos permitir a construção de caminhos à realização e à igualdade, para além da cultura comercial e machista, ainda hegemônica, que ameaça absorvê-la.

Movimento, Porto Alegre, v.12, n. 01, p. 11-29, janeiro/abril de 2006. 
Women on sport: corporealities and subjectivities

Abstract: Work that discusses corporeality and subjectivity - from the point of departure of the intimate connection between construction of the body and of identities - are taking on an everincreasing centrality within social theory today. One particularly pressing problem that has been studied refers to how particular "body projects" influence gender relations and, in particular, the ways in which they mold or act upon female subjectivity. This paper looks at results from research conducted in two different sports - professional volleyball and show jumping - in order to reflect upon the power of sport both to work as a space of transgressive and empowering notions and ways of "being a woman" and to tend toward mere reproduction (or creation of) patriarcal forms that discipline women's bodies and spirit.

Key words: Womem. Sport. Corporeality.

Mujeres en el deporte: Corporalidad y Subjetividad

Resumen: Los estudios sobre corporalidad y subjetividad que toman como su punto de partida las interconeciónes entre la construcción de cuerpos y identidades están ocupando cada vez más espacio en la teoria social contemporanea. Dentro destes, se plantea el problema da la centralidad de los "proyectos de cuerpo" en la cultura actual y como estos hacen parte de las relaciones de género, particularmente respecto a su poder de influenciar o moldar la subjetividad feminina. En el presente trabalho, presento algunas reflecciones sobre los resultados de una investigación de las experiencias e construcciones simbólicas de dos grupos de mujeres atletas (voleibol y equitación clássica/salto), con el objetivo mayor de pensar sobre las posibilidades que el deporte ofrece a las mujeres, como espacio de transgressión, empoderamiento, y/o de disciplinamiento patriarcal. Palabras-clave: Mujeres. Deporte. Corporalidad. 


\section{REFERÊNCIAS}

ADELMAN, Miriam. Mulheres Atletas: Re-significações da Corporalidade Feminina? Revista Estudos Feministas, Florianópolis. v. 11, n. 2, p. 445-265, 2003.

ADELMAN, Miriam.O desafio das amazonas: a construção da identidade de mulheres como atletas e amazonas do hipismo clássico (salto) brasileiro". In: SIMÕES, A.C., KNIJIK, Jorge D., O Mundo Psicossocial da Mulher no Esporte: Comportamento, Gênero, Desempenho. São Paulo: Aleph, 2004, p. 277-304.

BIRRELL, Susan, MC DONALD, Mary. Reading Sport: Critical Essays on Power and Representation. Boston: Northeastern University, 2000.

BORDO, Susan. Feminism, postmodernism, and gender skepticism. In: NICHOLSON, Linda J., org. Feminism/postmodernism: Thinking gender. New York: Routledge, 1994. p. 133-156.

BORDO, Susan. Twilight Zones: the Hidden Life of Cultural Images from Plato to OJ. Berkeley: University of California, 1997.

BRUMBERG, Joan Jacobs. The Body Project: an Intimate History of American Girls. New York: Random House, 1997.

BUTLER, Judith. Gender Trouble: Feminism and the Subversion of Identity. New York: Routledge, 1990.

DAVIS, Janet M., The Circus Age: Culture \& Society under the American Big Top. London: University of North Carolina Press.

FESTLE, Mary Jo. (1996) Playing Nice: Politics and Apologies in Women's Sports. New York: Columbia University, 2002.

GOELLNER, Silvana. Mulher e Esporte no Brasil: Fragmento de uma História Generificada". In: SIMÕES, A.C.; KNIJIK, Jorge D. O mundo psicossocial da mulher no esporte: comportamento, gênero, desempenho. São Paulo: Aleph, 2004. p. 359-374.

KEHL, Maria Rita. Deslocamentos do Feminino: a Mulher Freudiana na Passagem para a Modernidade. Rio de Janeiro: Imago, 1998.

LE COMPTE, Mary Lou. Cowgirls of the Rodeo: Pioneer Professional Athletes. Chicago: Illinois University, 1993.

LORBER, Judith. Paradoxes of Gender. New Haven: Yale University, 1994.

Movimento, Porto Alegre, v.12, n. 01, p. 11-29, janeiro/abril de 2006. 
MAGUIRE, Joseph. Global Sport: Identities, Societies, Civilization. Cambridge: Polity, 1999 .

MC EWEN, Christian. Jo's Girls: Tomboy Tales of High Adventure, True Grit and Real Life. Boston: Beacon, 1997.

OLIVEIRA, Pedro Paulo. A Construção Social da Masculinidade. Belo Horizonte: Editora UFMG, 2004.

SANT'ANNA, Denise Bernuzzi de. As infinitas descobertas do corpo. Cadernos Pagu, Campinas, v.14, p. 235-249, 2000.

Profa. Dra. Miriam Adelman Departamento de Ciências Sociais

Universidade Federal do Paraná Rua General Carneiro 4609 andar 80060-150 - Curitiba-PR miriamad@brturbo.com.br

Movimento, Porto Alegre, v.12, n. 01, p. 11-29, janeiro/abril de 2006. 